\section{Control of Government Expenditure on Research and Development}

In opening a debate on November 30 when the House of Commons was asked to take note of the First, Second and Third Reports from the Committee of Public Accounts in the Session 1960-61 and of the Special Report from that Committee, Mr. H. Wilson referred to the centenary of the establishment of the Committee in April 1861 and to the stealy development of its work. The debate covered a fairly wide field, but the two chief points of scientific interest are to be found in the reply of the Financial Secretary to the Treasury, Sir Edward Boyle. Sir Edward, referring to research and development practice, endorsed the Treasury Minute that it is Government practice to rely largely on private industry when it is a matter of design studies for complicated new weapons and equipment, subject to the checks which Government establishments can operate, and that research, development and production are integral parts of a continuous process to which the Ministry of Aviation's research establishments contribute by virtue of their specialized knowledge and facilities. Sir Edward also said that the major part of the Atomic Energy Authority's net cost of operations-nearly $£ 60$ million in 1959-60 -represents research and development effort in both the civil and military fields, and to publish the civil figures alone would make it easy to estimate the level of military research. Decisions on all matters concerned with the disclosure of information are taken after regular periodical reviews, and the importance of this issue to the Public Accounts Committee was realized. In principle, the Authority hoped to recover its research and development expenditure on civil reactor systems.

\section{Medical Men in Britain}

IN a debate in the House of Lords on November 29 on the shortage of medical men, Lord Taylor stressed the difficulty which non-teaching hospitals in Britain are experiencing in filling appointments. In replying for the Government, Lord Newton said that after reviewing the data and calculations of the Willink report, the Government is satisfied that the prospective demand for medical services will justify a rise in the university intake of pre-clinical students from Great Britain of 10 por cent above the 1,760 recom. mended by the Willink Committeo. The intake in July 1961 was 1,788 . The University Grants Committee has been asked to consider with the universities the implications of the Government's conclusion. Steps are being taken to improve the statistical information so far as reasonably possible. Lord Newton said that the Government intends to watch the figures constantly, including those of output from the medical schools, rather than attempt to make firm estimates at wide intervals of time. Lord Taylor had asserted that the shortage is now showing itself in the teaching hospitals also, and that the hospital service in Britain would have collapsed but for the influx of some 3,000-4,000 junior doctors from India and Pakistan. Lord Newton admitted that in March 1960 more than one-third of the posts in the middle and lower grades were occupied by doctors born outside Britain, but he emphasized the value of these doctors and the debt to their services. He said that in 1960 the average number of patients on a doctor's list was 2,287 , about 150 fewer than it was in 1952 , and that the improvement of the distribution of doctors was of special concern to the Medical Practices Committee constituted under the National Health Sorvice Act.

\section{Accelerators for Low-energy Nuclear Physics}

RECENT advances in the theoretical description of the atomic nucleus, together with recent design improvements in cyclotrons and Van de Graaff accelerators, have stimulated a special U.S. National Science Foundation programme for establishing and improving low-energy nuclear physies research facilities. The theoretical advances have resulted in a need for refined measurements of energy-levels, spin assignments, and other characteristics of the nucleus so that the synthesis of present theoretical models can be further advanced. Many of these refined measurements are now possible through extension of the range of Van de Graaff accelerators giving particles with energies of up to $20 \mathrm{MeV}$., and improvements in cyclotron design to permit well-eontrolled beams up to $40 \mathrm{MeV}$. Until about five years ago Van de Graaff accelerators were restricted to energies less than $8 \mathrm{MeV}$. Recently, the Foundation has made a group of six grants, totalling $4,161,500$ dollars, in furtherance of the new programme. These six accelerators are expected to play an important part in the netion's effort in nuclear structure physics. Grants made so far in this special programme are as follows: University of Chicago, 296,700 dollars for a 4-MeV. Van de Graaff machine to be used by Dr. S. K. Allison and his Group; Michigan State University, 700,000 dollars toward a $40-\mathrm{MeV}$. cyclotron for the use of Dr. Henry G. Blosser's research team; Univer. sity of Pittsburgh, 977,600 dollars toward an $18-\mathrm{MeV}$. three-stage Van de Graaff machine for research under the direction of Dr. Bernard L. Cohen; University of Washington (Seattle), 1,240,000 dollars toward a 22-MeV. three-stage Van de Graaff machine for the Physics Department, of which Dr. Ronald Geballe is executive officer; Ohio State University, 499,200 dollars for a $5 \cdot 5-\mathrm{MeV}$. Van de Graaff machine for the Department of Dr. H. H. Nielsen; State University of Iowa (Iowa City), 498,000 dollars for a 5.5-MeV. Van de Graaff machine for the Department under Dr. James A. Van Allen.

The Royal Commission for the Exhibition of 1851

The eleventh report of the Commissioners for the Exhibition of 1851 covers the activities of the Royal Commission since its tenth report was issued in May 1951 (Pp. 32. (Cmnd. 1502.) London: H.M.S.O., 1961. 2s. 6d. net). The general pattern of the Science Research Scholarships has remained unchanged, but the list of universities invited to participate has been extended and the value of the awards increased to $£ 550$ a year for Overseas Scholars and $£ 800$ a year for senior students, exclusive of allowances. In 1958 the National Research Couneil of Canada offered to each 1851 Scholar from Canada a bonus of $£ 250$ a year from its own funds, which has been particularly useful to married Scholars. Similar arrangements have been made, with various qualifications, by authorities in Australia, South Africa, India, Pakistan and New Zealand. Since 1952 the Commission has co-operated with the Council of the Royal Society in the administration of the Rutherford Scholarship. The value of the Postgraduate Scholarship in Naval Architecture was in 1958 increased to $£ 600$ a year. In view of the re-allocation of so much of the property on the Kensington Gore Estate in 1956, it was agreed with the Imperial College of Science and Technology 